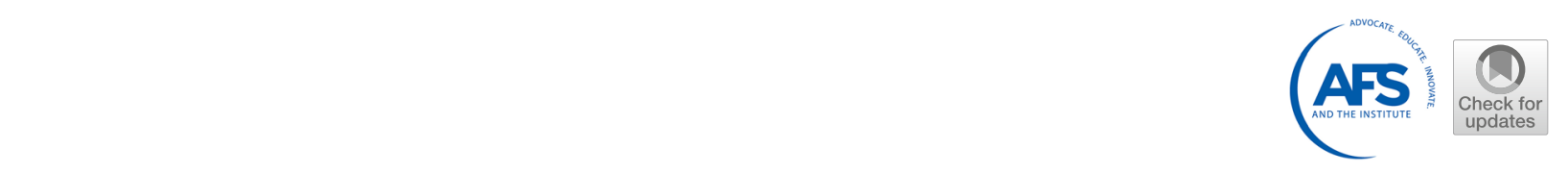

\title{
MECHANICAL RESPONSE OF Ni-BASED CU5MCUC ALLOY TO DIFFERENT STABILIZATION THERMAL TREATMENTS
}

\author{
Andrea Gruttadauria, Silvia Barella, and Claudia Fiocchi \\ Mechanical Department, Politecnico di Milano, Milan, Italy
}

Copyright $@ 2020$ The Author(s)

https://doi.org/10.1007/s40962-020-00519-x

\begin{abstract}
The Ni-Fe-Cr system is the basis of a series of commercial alloys featuring chemical-physical characteristics that allow them to be used in a variety of fields where excellent resistance to aggressive environments is required. In this scenario, the CU5MCuC alloy, the foundry counterpart of Alloy 825 , is proving successful in the petrochemical field thanks to its good corrosion resistance in acidic and highly oxidizing environments. Intergranular corrosion resistance, critical for this material, is ensured by the stabilization treatment that allows precipitation of $\mathrm{Nb}$ carbides. Strengthening of this alloy takes place only via a solid

combinations of time and temperature, were carried out in order to modify the material's microstructure. After the thermal treatments, microstructural analyses, mechanical tests and (pitting and intergranular) corrosion and resistance tests were carried out to identify optimal treatment parameters in order to promote the evolution of microstructural constituents capable of improving mechanical strength without decreasing corrosion resistance. The treatment that achieves the best compromise between mechanical properties and corrosion resistance is stabilization at $970{ }^{\circ} \mathrm{C}$ for $4 \mathrm{~h}$.
\end{abstract} solution. Therefore, its mechanical properties depend on the solution annealing treatment: often this treatment alone does not make it possible to reach the UTS imposed by the ASTM-A494 standard. In this work, the possibility of using stabilization treatment to increase mechanical strength as well was considered. Treatments, with different
Keywords: CU5MCuC alloy, alloy 825, nickel foundry, stabilization treatment, corrosion resistance, mechanical properties

\section{Introduction}

Nickel-based alloys are widely used in the modern industry because of their ability to work in the presence of elevated temperatures, high stresses and corrosive environments or combinations of the same. ${ }^{1,2}$ They have applications in critically important components in chemical, petrochemical and nuclear processes as well as in marine and aeronautical applications. ${ }^{3,4}$ High corrosion resistance makes nickel an excellent base for the development of specialized alloys, such as CU5MCuC, which gains superior corrosion resistance thanks to the additions of chromium and molybdenum. ${ }^{5}$ However, intergranular corrosion, due to sensitization, is one of the most serious problems of this alloy, which could result in unexpected failures and lead to huge losses.
CU5MCuC is a foundry alloy, the casting structure has intrinsic problems due to solidification structures, i.e. segregation, dendritic structure, and porosity and cannot be processed using thermomechanical processing (forging, rolling, etc.) to obtain a uniform and fine microstructure that guarantees good mechanical properties. ${ }^{5}$ On the other hand, nickel is characterized by an austenitic FCC-matrix, able to dissolve extensive amounts of elements in various combinations. For this reason, solid-solution strengthening is the way to improve the mechanical properties of CU5CuMC. The strongest solid-solution hardeners in this case are $\mathrm{Mo}, \mathrm{Nb}$ and $\mathrm{Cu}$, whilst $\mathrm{Fe}$ and $\mathrm{Cr}$ can be classified as weaker solid-solution strengtheners. ${ }^{6,7}$

Nevertheless, manufacturers are encountering some difficulties in complying with mechanical requirements (mainly the ultimate tensile stress) prescribed by ASTM-A494. ${ }^{8}$ Since strengthening by plastic deformation and/or 
recrystallization is not possible, one of the possible solutions is to improve the mechanical properties by precipitation hardening. ${ }^{9}$ The chemical composition of this alloy is not suitable for this kind of strengthening mechanism, but some precipitation can be originated in relation to the stabilization treatment. ${ }^{7}$ The sensitization of the grain boundary, due to the depletion of $\mathrm{Cr}$ with the formation of $\mathrm{M}_{23} \mathrm{C}_{6}$ precipitates at grain boundaries, can be avoided using the stabilization treatment as a prevention measure. ${ }^{10-12}$ For that, the counterpart Alloy 825 is alloyed with Ti to promote stability of carbides. In the CU5CuMC alloy, adding niobium together with a stabilization thermal treatment, overcomes the sensitization, bringing about the formation of stable $\mathrm{Nb}$ carbides. ${ }^{13-15}$ However, detailed studies of precipitation in these alloys are rare.

The aim of this is to study the possibility of increasing mechanical properties by means of the stabilization treatment, using different time-temperature combinations. It is important to underline that stabilization is not normally done to strengthen the alloy but, since it is not possible to modify the chemical composition, even small influences on material performance are beneficial. In the CU5CuMC alloy, precipitates rich in molybdenum, silicon and niobium assume different shapes, volume fraction and dimensions depending on the time-temperature combinations applied. As is well known, large precipitates are incoherent, and the strengthening effect is limited but this can help to obtain the desired mechanical properties. Some evidence $^{15}$ also suggests that the shape of the precipitate can improve the yield strength, in particular, acicular long and thin precipitates seem to confer a greater strengthening effect than globular ones.

The study points out the double effect of stabilization in preventing sensitization and the consequent intergranular corrosion, and improving mechanical strength.

\section{Experimental Procedures}

CU5MCuC $(30 \times 50 \times 200 \mathrm{~mm})$ ingots were obtained by sand casting. 10 ingots were cast in the same mould and from the same casting at a pouring temperature around $1470{ }^{\circ} \mathrm{C}$. The ingots have solidified and cooled at room temperature in the mould and removed after $24 \mathrm{~h}$. The chemical composition of the cast is listed in Table 1.
The ingots were solution annealed (SA) for $4 \mathrm{~h}$ at $1220^{\circ} \mathrm{C}$ and water quenched before undergoing stabilization treatments featuring different time-temperature combinations. The solution annealing parameters were chosen according with the practice of the foundry that casted the alloy: with these parameters it is certain that the chemical composition and microstructure have been homogenized by eliminating chemical gradients due to segregation. The temperatures were chosen in order to cover the whole range prescribed by the standard (ASTM-A494): $940{ }^{\circ} \mathrm{C}, 960{ }^{\circ} \mathrm{C}, 970{ }^{\circ} \mathrm{C}$ and $990{ }^{\circ} \mathrm{C}$ lasting $30 \mathrm{~min}, 2 \mathrm{~h}$ and $4 \mathrm{~h}$ (Figure 1).

Microstructure examination was conducted by optical microscopy (OM) and scanning electron microscopy (SEM) after sample preparation according to ASTM E407$07,{ }^{16}$ using acetic-glyceregia as an etchant solution. SEM is equipped with EDS (energy dispersive spectroscopy) and BSE (back-scatter electron) probes to detect the chemical composition. Tensile tests were performed in accordance with ASTM E8/E8M-16a (Specimen 3). ${ }^{17}$ Tests were carried out at room temperature applying a cross-head speed of $2 \mathrm{~mm} / \mathrm{min}$, both on solution annealed samples (SA) and on stabilized ones. Three repetitions for each condition were performed. The material's response to localized corrosion in oxidizing chloride environments was measured according to ASTM G48-11 (Method A) ${ }^{18}$ and was performed on the solution annealing (SA) sample, for the $30 \mathrm{~min}$ and $4 \mathrm{~h}$ stabilized specimens. All samples were polished with a 120-grit abrasive paper and the weights and total exposed area are computed before the test beginning. Specimens were immersed in the test solution (100 g of ferric chloride $\mathrm{FeCl} 3: 6 \mathrm{H} 2 \mathrm{O}$ and $900 \mathrm{~mL}$ reagent water) at room temperature for $72 \mathrm{~h}$. At the end of the period, samples were removed from the solution and cleaned to remove corrosion products from deep pits. Samples are weighted also at the end of the test in order to evaluate their weight loss.

The susceptibility to intergranular corrosion was evaluated according to ASTM G28-02 (Method A) ${ }^{19}$ and was performed on $4 \mathrm{~h}$ stabilized specimens. The test was performed in boiling ferric sulphate-50\% sulphuric acid solution, simulating an aggressive environment which could be encountered in service. Specimens are polished with wet 400-grid abrasive paper, weighted and then immersed in the boiling solution for $120 \mathrm{~h}$. At the end of the experiment, weight loss is measured and the corrosion rate is computed in $\mathrm{mm} / \mathrm{y}$.

Table 1. CU5MCuC chemical composition (\%wt)

\begin{tabular}{|c|c|c|c|c|c|c|c|c|c|c|}
\hline C & $\mathrm{Mn}$ & $\mathrm{Si}$ & $P$ & $S$ & $\mathrm{Cu}$ & Mo & $\mathrm{Fe}$ & $\mathrm{Ni}$ & $\mathrm{Cr}$ & $\mathrm{Nb}$ \\
\hline 0.031 & 0.848 & 0.871 & 0.010 & 0.001 & 2.619 & 3.315 & 26.392 & Bal. & 23.042 & 0.724 \\
\hline
\end{tabular}




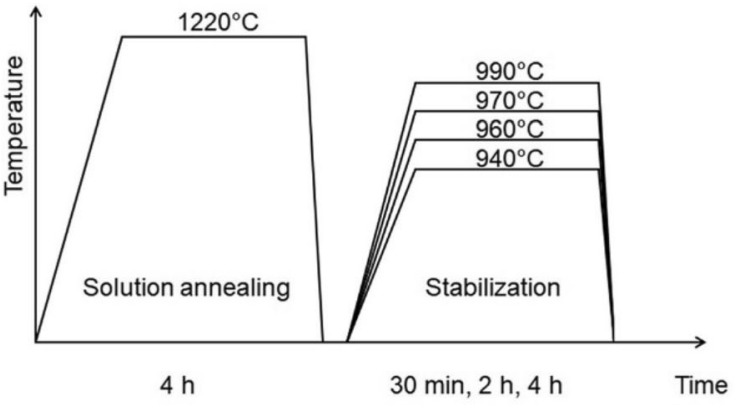

(a)

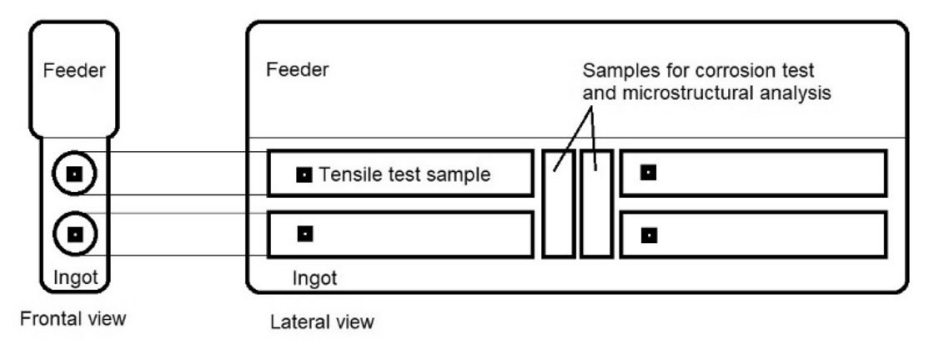

(b)

Figure 1. Scheme and parameters of the thermal treatments performed (a) and scheme of the sample withdrawal for tensile and corrosion test (b)

From each ingot, four tensile test specimens and two samples for corrosion tests and microstructural analysis were machined by electrical discharge machining as reported in the sketch in Figure 1b.

\section{Result}

The microstructure analysis and the description of precipitates are detailed below. In Figure 2, representative examples of the solution annealed microstructure and of a stabilized sample are shown.

The SA sample shows a classical solid solution structure, the grains have large dimensions, as expected for a cast structure, and no evidence of precipitation is present. The dark points are defects such as porosity or non-metallic inclusions. After stabilization, secondary phases are embedded in the grain. The solidification dendritic pattern is in the background; very thin carbides are located at the secondary and ternary interdendritic spaces. Moreover, a huge amount of secondary phases is present; they are evenly dispersed in the grain and at the grain boundary as a chain featuring discontinuous precipitation. ${ }^{20,21}$
Figure 3 shows the collection of micrographs for the different stabilization conditions.

As said previously, massive precipitation is observed: for short soaking time, precipitation is favoured at grain boundaries and, as the time increases, precipitates also nucleate and grow into the grain. The precipitates are irregular in shape and, as maintenance time increases, they increase in number, and coalesce..$^{22}$ At $970{ }^{\circ} \mathrm{C}$ and $990{ }^{\circ} \mathrm{C}$, acicular precipitates form in the grains but not in the boundaries with a remarkable difference: at $970{ }^{\circ} \mathrm{C}$ they are thin of about $15 \mu \mathrm{m}$ in length, whilst at $990{ }^{\circ} \mathrm{C}$ they are stocky and shorter (Figure 4).

Figure 5 shows the dependence of the precipitates volume fraction in relation to the stabilization parameter. No appreciable trend was recorded with respect to the soaking temperature: low temperatures resulted in smaller precipitates homogenously dispersed, high temperatures involved less dispersion of chubby ones.

In Figure 6 and in Table 2 the SEM-EDS analysis is shown. All the pictures refer to soaking lasting $4 \mathrm{~h}$ at different temperatures. As observed previously, whilst commenting on optical micrographs, 30 min-stabilization
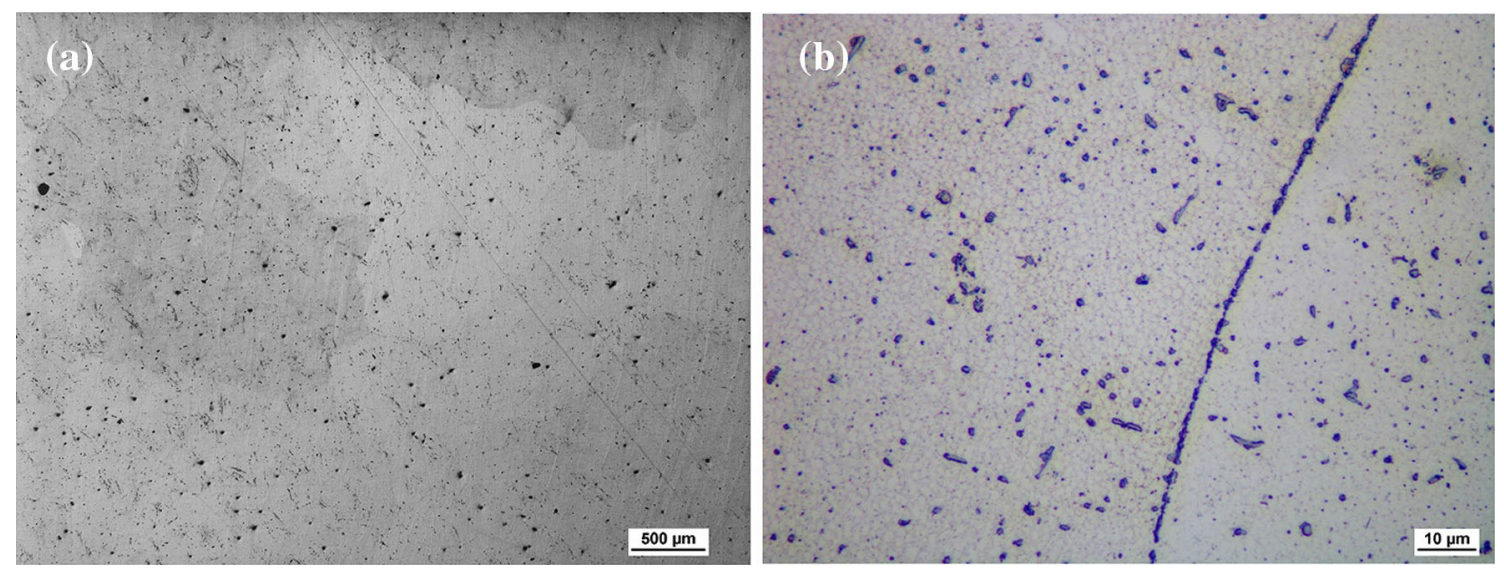

Figure 2. Representative microstructure of the material: SA (a) and sample stabilized at $990^{\circ} \mathrm{C}, 4 \mathrm{~h}$ (b) 


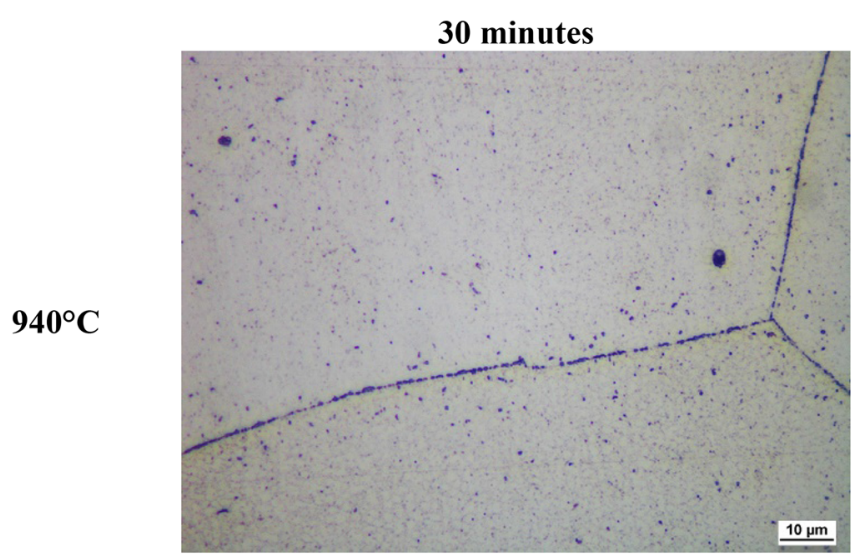

(a)

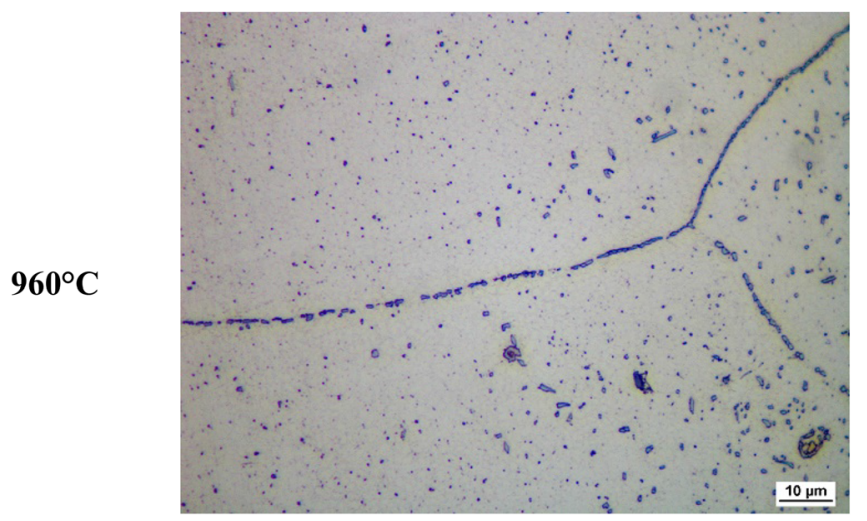

(c)

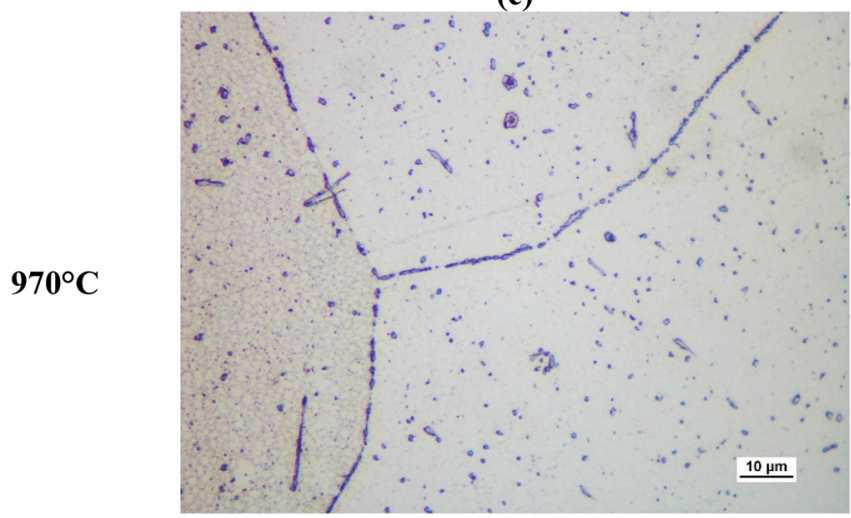

(e)

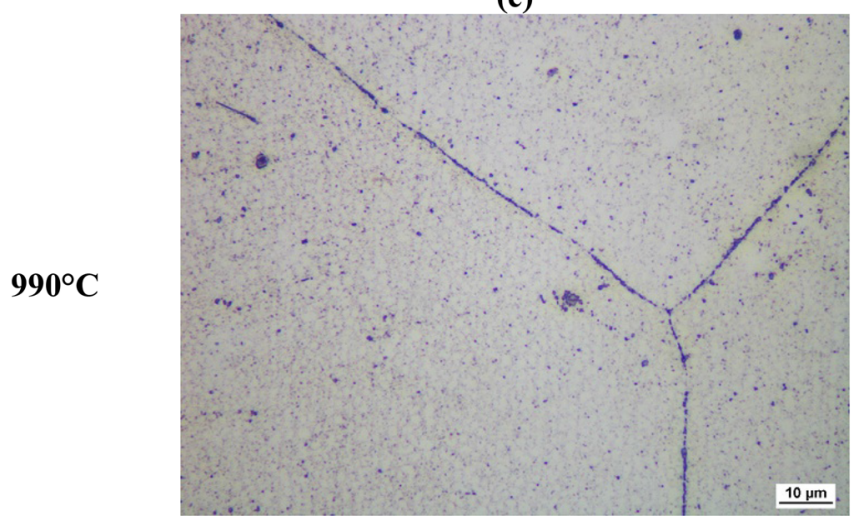

(g)

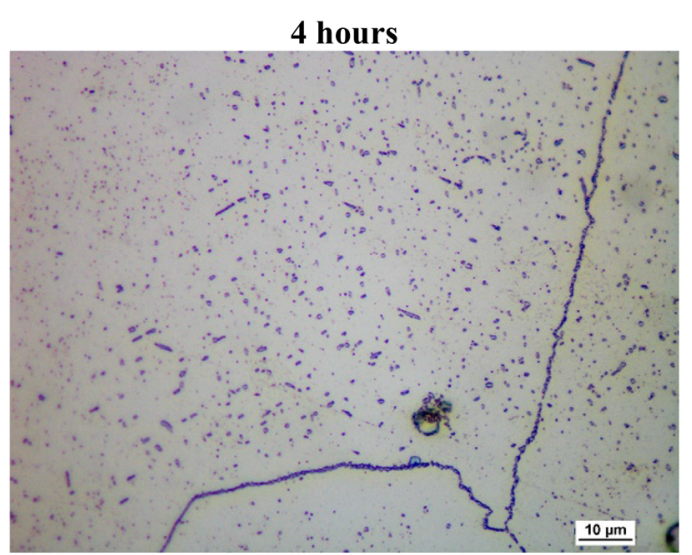

(b)

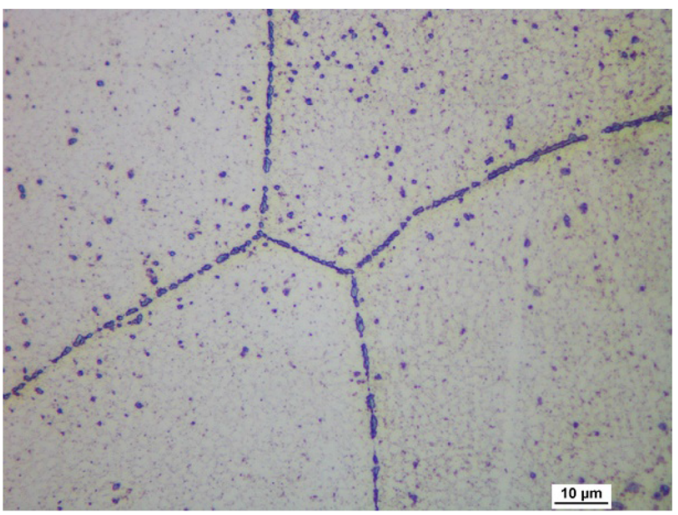

(d)

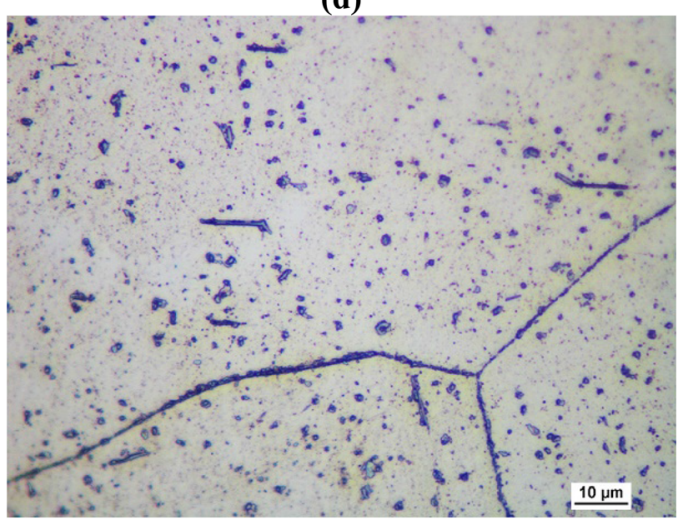

(f)

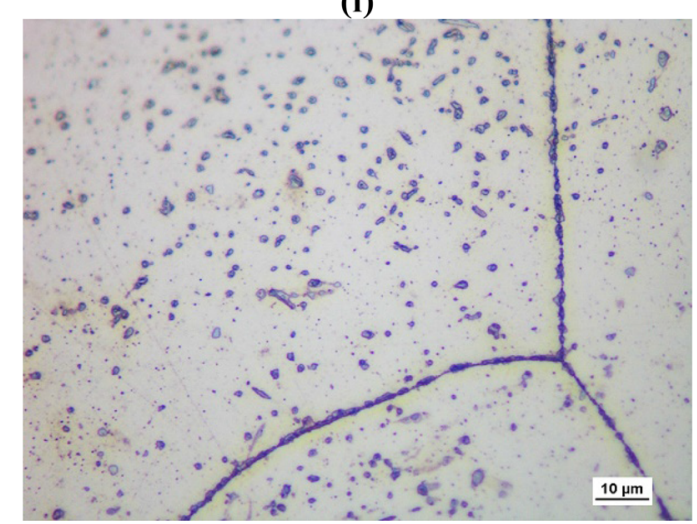

(h)

Figure 3. Precipitations after different stabilization heat treatments by optical microscopy 

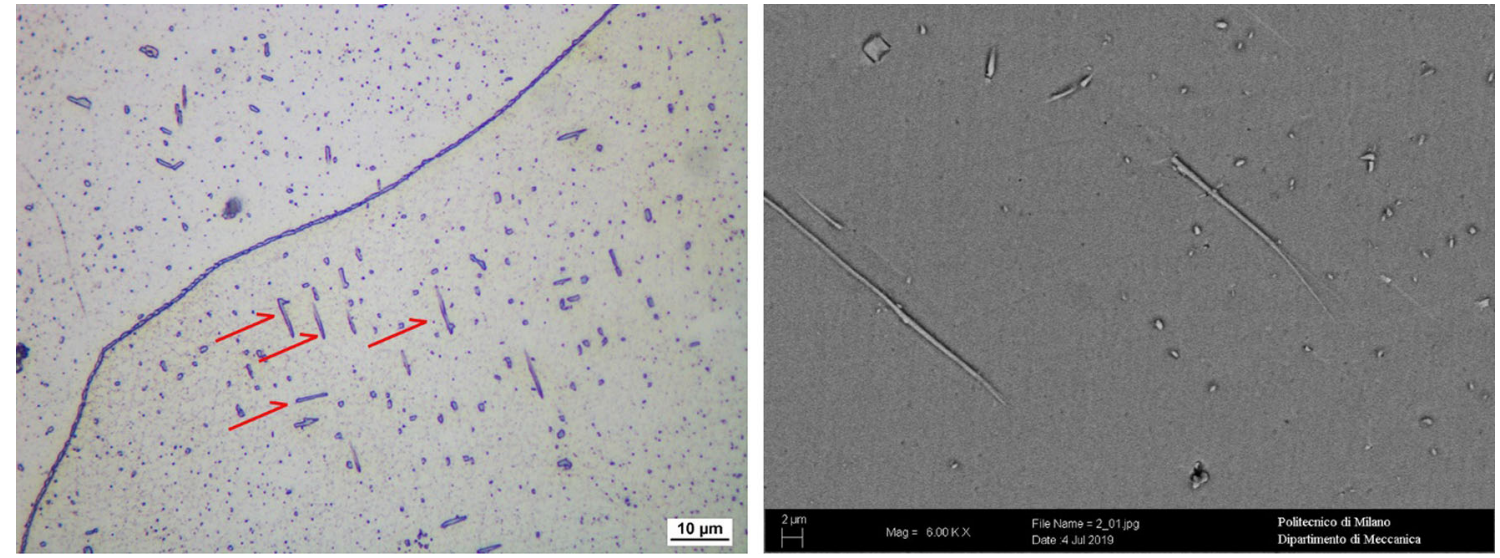

Figure 4. Image of acicular precipitates (red arrows) in the sample treated at $970{ }^{\circ} \mathrm{C}$ for $4 \mathrm{~h}$

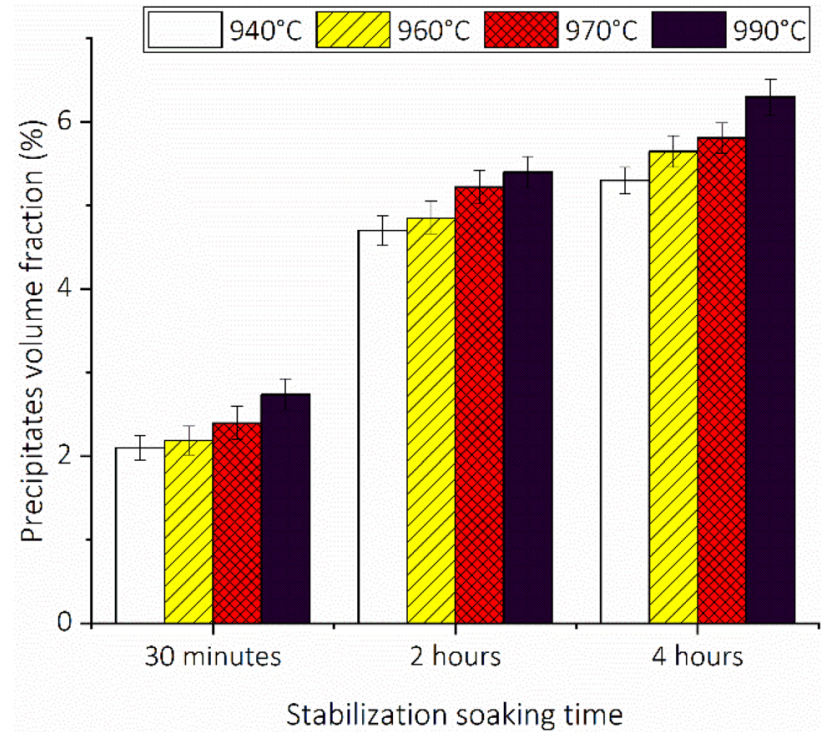

Figure 5. Precipitation volume fraction for different soaking time and temperature

treatment causes the formation of very thin precipitates and their chemical composition cannot be detected using the EDS detector, and the same applies to $2 \mathrm{~h}$ treatment. The dimension of the precipitates is enough to allow a chemical composition analysis only after $4 \mathrm{~h}$ of heat treatment.

At higher magnification, the grain boundary appears as an agglomeration of precipitates which are characterized at any temperature by $\mathrm{Nb}, \mathrm{Si}$ and $\mathrm{Mo}$, whilst the $\mathrm{Cr}$ amount is lower than the nominal. That confirms no precipitation of $\mathrm{Cr}$ carbides, as expected for this treatment. Near the grain boundary, the $\mathrm{Cr}$ content is coherent with the chemical composition of the material and $\mathrm{Cu}$ is higher. The precipitates within the grain are mainly $\mathrm{Nb}-\mathrm{Mo}$ carbides as well as the acicular precipitates. The composition of the acicular precipitates features $\mathrm{Ni}$ at an $(\mathrm{Nb}+\mathrm{Mo})$ atomic ratio 2:1, ascribable to the $\delta$-phase. At $990{ }^{\circ} \mathrm{C}, \mathrm{Nb}$-rich particles are favoured, probably carbides.
Figure 7 shows the ultimate tensile strength data; the horizontal line marks the minimum limit of $520 \mathrm{MPa}$ prescribed by ASTM A494. The stabilization treatment provokes a tensile strength improvement only in the case of solution annealed specimens, making the material comply with the specification.

The graph shows that, at $940{ }^{\circ} \mathrm{C}$ and $960{ }^{\circ} \mathrm{C}$, stabilization time does not influence the tensile strength. Slight trends can be observed for higher temperatures: at $970{ }^{\circ} \mathrm{C}$, tensile strength appears to slightly improve as stabilization time increases; the best performance corresponds to a permanence time of $4 \mathrm{~h}$ at $970{ }^{\circ} \mathrm{C}$. On the contrary, $990{ }^{\circ} \mathrm{C}$ stabilization exhibits an opposite trend and the $4 \mathrm{~h}$ treatment seems not to improve material tensile strength at all, making it not conform to the specification.

By looking at the yield strength results shown in Figure 8, stabilization imparts an improved yield strength only in relation to solution annealed samples. A trend in terms of soaking time or temperature is not substantial. The elongation decreases subsequently to the execution of stabilization heat treatment for all the time-temperature combinations performed.

Figure 9 shows the result of the G48 test; solution annealed (SA) samples are almost immune from pitting corrosion. For a soaking time of $30 \mathrm{~min}$, the pitting resistance increases with an increase in the stabilization treatment; after $4 \mathrm{~h}$ stabilization, the differences are negligible and the sample stabilized at $990{ }^{\circ} \mathrm{C}$ shows the best behaviour.

G28 test shows that samples that have undergone $4 \mathrm{~h}$ stabilization treatment at $970{ }^{\circ} \mathrm{C}$ give the lowest corrosion rate (Figure 10). According to the literature, ${ }^{23,24}$ corrosion rates of $0.5 \mathrm{~mm} / \mathrm{year}$ are considered acceptable for ASTM G28 testing of wrought Alloy 825. This means that the only acceptable values are those that correspond to specimens treated at $970{ }^{\circ} \mathrm{C}$ and $990{ }^{\circ} \mathrm{C}$. 


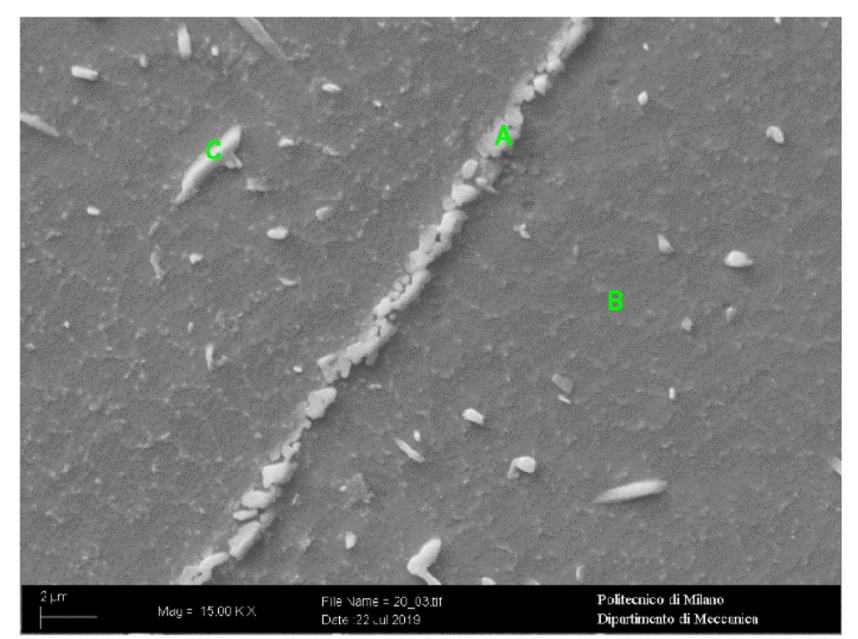

$940^{\circ} \mathrm{C}$

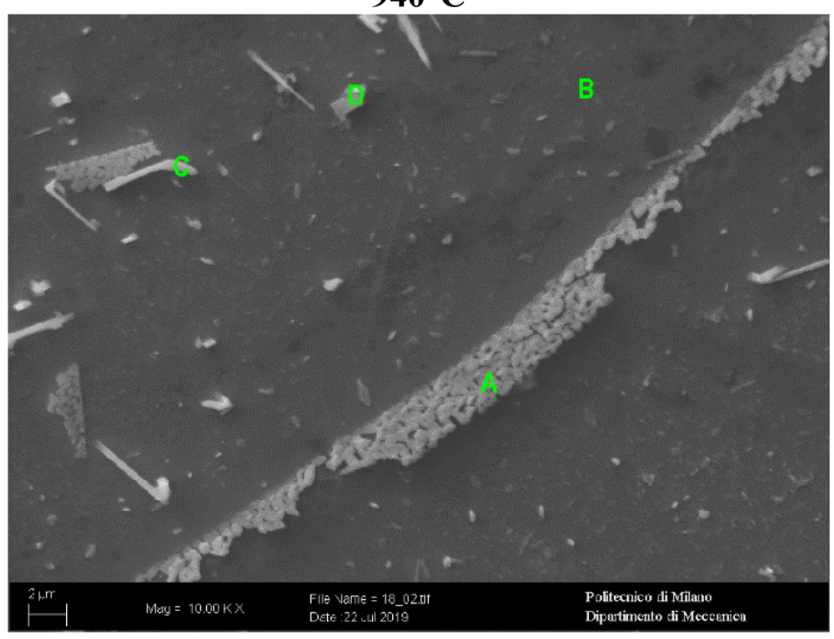

$970^{\circ} \mathrm{C}$

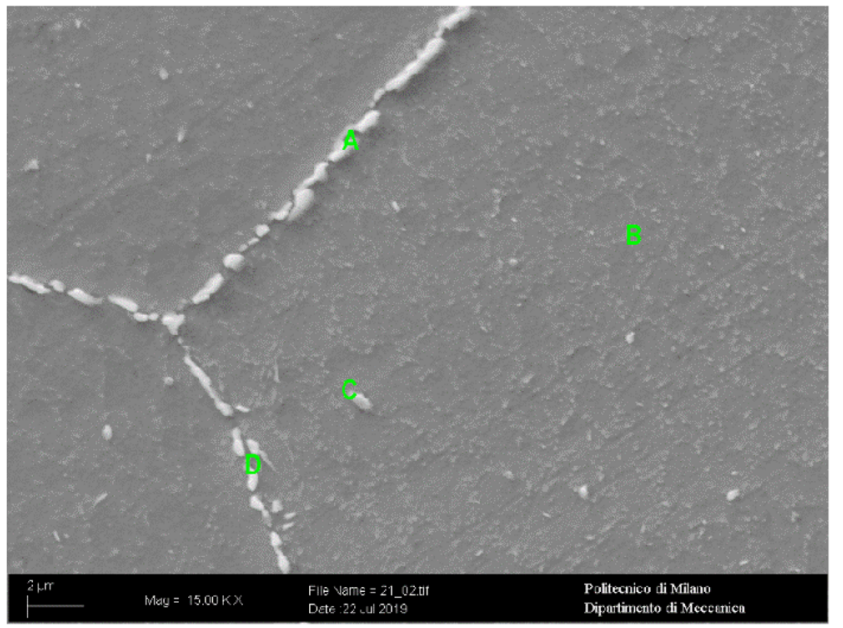

$960^{\circ} \mathrm{C}$

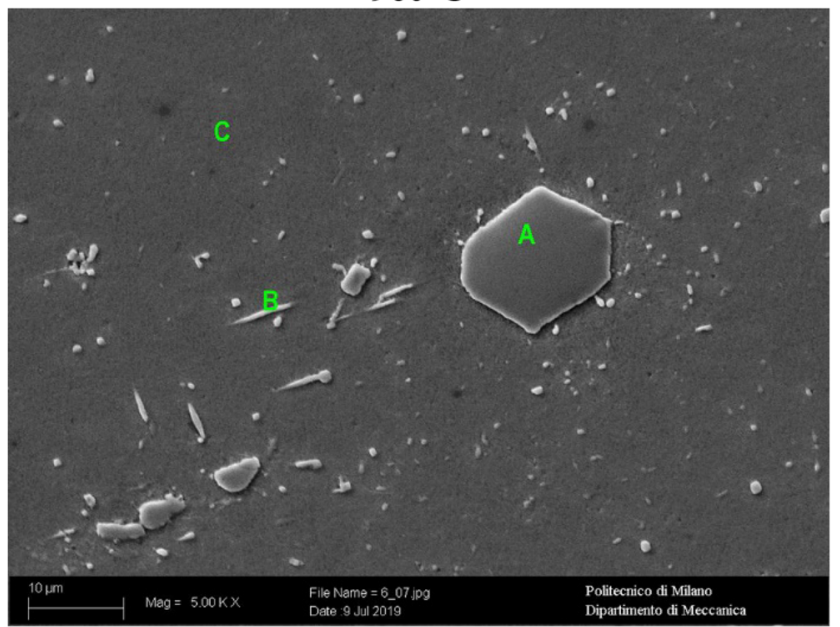

$990^{\circ} \mathrm{C}$

Figure 6. SEM micrographs for different soaking stabilization temperatures after $4 \mathrm{~h}$ treatments

\section{Discussion}

During solidification, Mo and $\mathrm{Nb}$ tend to segregate in the interdendritic regions, and the increase in solutes is responsible for the precipitation of primary carbides. They are of a stable MC type, and most of them were not affected by solution annealing, remaining dispersed in the matrix. On the other hand, molybdenum and niobium segregation is balanced by the inverse segregation of iron that remains preferentially in solution. $\mathrm{Nb}$ also retards the decomposition of primary (Nb-Mo)C carbides into $\mathrm{Cr}_{23} \mathrm{C}_{6}$, whilst Mo favours the formation of $\mathrm{Mo}_{6} \mathrm{C}$. The exposure to the stabilization temperature induces the formation of these secondary carbides by the transformation of the primaries: this transformation reduces the amount of carbon available for $\mathrm{M}_{23} \mathrm{C}_{6}$ that are responsible for sensitizing when the material is exposed to a critical temperature. ${ }^{6,24}$

Moreover, Mo and $\mathrm{Nb}$ avoid the precipitation of $\mathrm{Cr}_{23} \mathrm{C}_{6}$ at the grain boundary after solution heat treatment: indeed, the chromium concentration remained almost constant in the entire matrix avoiding deleterious depletion at grain boundaries and so the tendency to intergranular corrosion. $^{18,19}$ In addition, at the stabilization temperature, chromium can diffuse from the matrix to re-establish equilibrium after carbide formation and precipitation, avoiding the formation of chromium depleted zones. ${ }^{24,25}$

Grain boundaries are adorned with chain precipitates rich in $\mathrm{Nb}$ and $\mathrm{Mo}$ that are not detrimental for corrosion resistance; no increase in $\mathrm{Cr}$ content testifies the presence of $\mathrm{MC}$ or $\mathrm{M}_{6} \mathrm{C}$ carbides. The needle-like precipitates, encountered at higher temperature, show higher $\mathrm{Nb}$ and $\mathrm{Mo}$ content compared to the precipitates formed at a lower soaking temperature. This suggests that they could be classified as $\delta$-phases. $\delta$ - $\mathrm{Ni}_{3}(\mathrm{Nb}, \mathrm{Mo})$ phase is an intermetallic equilibrium that can form directly from the supersaturated solid solution after exposure at relatively high temperatures, or as a replacement for the metastable $\gamma^{\prime \prime}-\mathrm{Ni}_{3} \mathrm{Nb}$ phase. ${ }^{26}$ According to the literature, $\delta$-phases are found to be present in Ni-based alloys exposed to temperatures in the range $815-990{ }^{\circ} \mathrm{C}$, and they generally are located both at the grain boundary and inside the grain, where $\gamma^{\prime \prime}$-particles nucleated. ${ }^{2,21}$ In this alloy, the 
Table 2. EDS chemical composition of the precipitates shown in Figure 6

\begin{tabular}{|c|c|c|c|c|c|c|c|}
\hline wt\% & $\mathrm{Si}$ & $\mathrm{Cr}$ & $\mathrm{Fe}$ & $\mathrm{Ni}$ & $\mathrm{Cu}$ & $\mathrm{Nb}$ & Mo \\
\hline \multicolumn{8}{|c|}{$940^{\circ} \mathrm{C} \_4 h$} \\
\hline$A$ & 2.43 & 21.18 & 22.47 & 37.68 & 2.62 & 5.65 & 6.93 \\
\hline B & 1.11 & 22.69 & 25.77 & 42.00 & 2.88 & 0.59 & 2.97 \\
\hline$C$ & 2.86 & 20.10 & 21.09 & 37.73 & 3.44 & 6.67 & 7.36 \\
\hline \multicolumn{8}{|c|}{$960^{\circ} \mathrm{C} \_4 h$} \\
\hline$A$ & 3.35 & 19.78 & 20.31 & 36.26 & 2.35 & 8.57 & 8.56 \\
\hline B & 1.28 & 22.45 & 26.53 & 40.30 & 2.65 & 0.78 & 3.30 \\
\hline C & 0.91 & 22.87 & 21.71 & 30.70 & 2.20 & 3.70 & 17.09 \\
\hline $\mathrm{D}$ & 1.46 & 22.15 & 25.73 & 39.30 & 2.35 & 2.65 & 4.78 \\
\hline \multicolumn{8}{|c|}{$970^{\circ} \mathrm{C} \_4 h$} \\
\hline$A$ & 3.12 & 19.81 & 21.03 & 36.75 & 2.67 & 6.67 & 8.90 \\
\hline B & 1.02 & 22.09 & 25.58 & 41.41 & 3.47 & 1.70 & 3.62 \\
\hline C & 4.52 & 17.44 & 13.92 & 33.44 & 1.77 & 14.14 & 14.24 \\
\hline $\mathrm{D}$ & 4.65 & 16.59 & 12.72 & 29.86 & 1.82 & 15.75 & 15.01 \\
\hline \multicolumn{8}{|c|}{$990^{\circ} \mathrm{C} \_4 h$} \\
\hline A & 0.05 & 0.73 & 0.30 & 0.51 & - & 68.86 & 0.64 \\
\hline B & 3.65 & 18.81 & 16.82 & 34.09 & 2.21 & 11.73 & 12.22 \\
\hline C & 1.31 & 22.17 & 27.21 & 40.63 & 2.99 & 0.34 & 4.16 \\
\hline
\end{tabular}

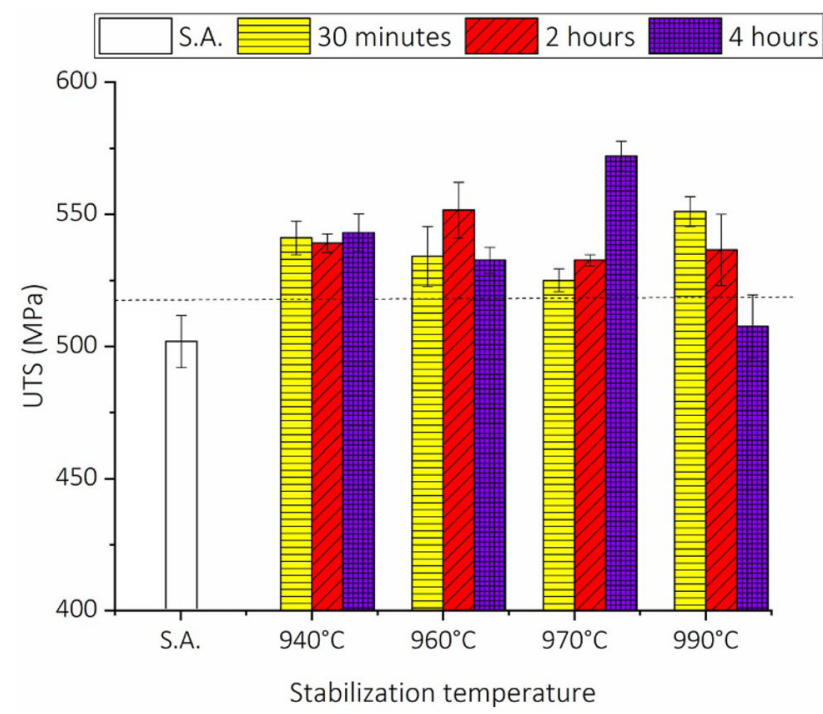

Figure 7. Ultimate tensile strength trend for different time-temperature combinations of stabilization treatments

upper limit of the temperature range for $\delta$-phase precipitation seems to be shifted to higher temperatures, since they clearly form both at $970{ }^{\circ} \mathrm{C}$ and $990{ }^{\circ} \mathrm{C}$, maybe because of the relatively low amount of $\mathrm{Nb}$ in the material composition. As in this case, $\delta$-particles generally have a needle, plate like shape as well as globular morphology. They generally nucleate at grain boundaries, but at high temperatures also form in an intragranular fashion. The driving force for $\delta$-phase formation is niobium; if $\mathrm{Nb}$ content increases the $\delta$-phase volume fraction can increase: the $\mathrm{Nb}$ segregation can act as a nucleant. ${ }^{27}$

Compared to the SA condition, the increase in UTS after stabilization is due to the precipitation of compounds with a strengthening effect, which are not present in the solution annealed condition, characterized by the dissolution of almost all the alloying elements. UTS is improved by the presence of discrete particles, which act by hindering dislocation movements. The different behaviour of samples treated at $970{ }^{\circ} \mathrm{C}$ and $990{ }^{\circ} \mathrm{C}$ could be explained through microstructural differences, and in particular may be due to the different morphology of $\delta$ phases. $\delta$ are orthorhombic $\mathrm{Ni}_{3} \mathrm{Nb}$ ( $\mathrm{Nb}$ coupled with $\mathrm{Mo}$ ) intermetallic compounds in nickel- and iron-nickel-based super alloys. ${ }^{26}$ The $\delta$-phases are useful for controlling the structure of wrought ironnickel and nickel-based super alloys during processing. ${ }^{28}$ In particular, the ones formed at $970{ }^{\circ} \mathrm{C}$ are thinner and longer, with lengths greater than $10 \mu \mathrm{m}$, whilst at $990{ }^{\circ} \mathrm{C}$ thicker and shorter needles are observed. According to literature, $\delta$ precipitates can have an effect on stress rupture, but when they get coarser and in higher amounts they degrade mechanical properties. ${ }^{15,28}$

Regarding yield strength and elongation, no effective trends are appreciable. Conversely to the case of tensile strength, yielding appears not to be affected by stabilization time and temperature. The drop in A \% should be due to the fact that in the solution annealed samples no precipitation strengthening occurs, as almost all the elements are dissolved in solid solution. As subsequent stabilization is performed, precipitation causes the elongation at break to decrease: failure can initiate either by particle fracture or by decohesion of the precipitate/matrix interface. ${ }^{13}$ Elongation values are almost constant for all stabilized specimens and satisfy specification requirements in all conditions; different time-temperature combinations do not influence their values, as stabilization is not intended to improve mechanical performances, and only slightly influences tensile strength.

The solution annealed condition shows better pitting resistance because of the dissolution of the majority of the precipitates: elements such as $\mathrm{Cr}$ and, even better, Mo, remain in solution and confer resistance to localized corrosion. ${ }^{23}$ Stabilized samples are subjected to a more evident weight loss with an interesting trend due to the precipitation behaviour. At $940{ }^{\circ} \mathrm{C}$ and $960{ }^{\circ} \mathrm{C}$, for a short stabilization time, the precipitation can be ascribed mainly to $(\mathrm{Nb}-\mathrm{Mo}) \mathrm{C}$ or $\mathrm{MO}_{6} \mathrm{C}$, denuding the matrix of $\mathrm{Mo}$ : as $\mathrm{Mo}$ is added in order to optimize the alloy's behaviour in oxidizing chlorine environments, its depletion in the matrix induces a loss in localized corrosion resistance performance. ${ }^{29}$ At higher temperature, the formation of $\delta$-phase and $\mathrm{Cr}_{23} \mathrm{C}_{6}$ reduces the formation of Mo-based carbides, 


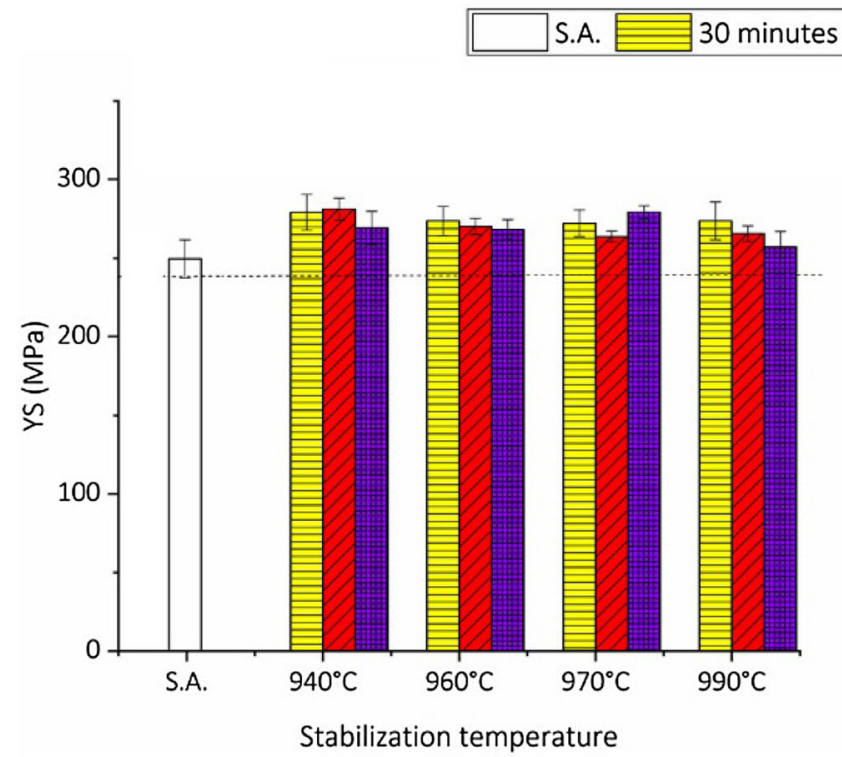

(a)

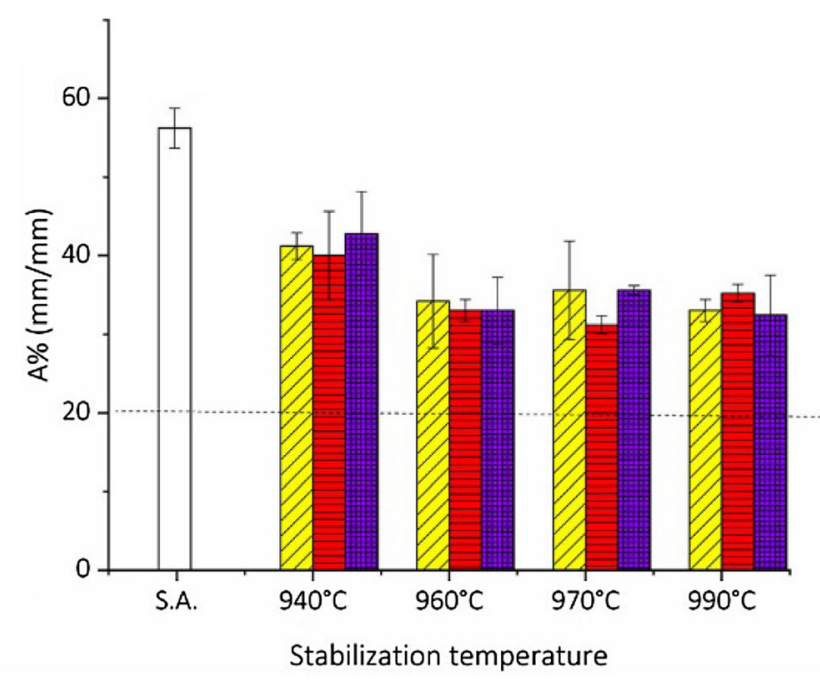

(b)

Figure 8. Yield strength (a) and elongation (b) trend for different time-temperature combinations of stabilization treatment

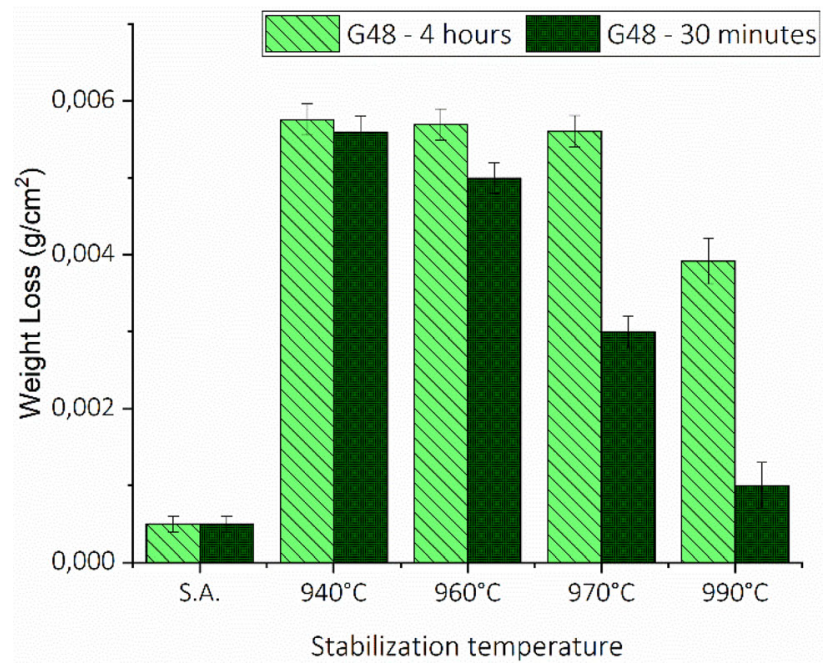

Figure 9. Weight loss induced by the ferric chloride pitting test (G48) for different stabilization times: $30 \mathrm{~min}$ (a) and $4 h$ (b)

increasing pitting resistance. For longer exposure times, precipitate growth takes place reducing Mo in the matrix for all the stabilization conditions that respond in the same manner to pitting. Cr content is believed to be responsible for pitting corrosion initiation, whilst Mo appears to control the material's repassivation ability. ${ }^{30}$ Nickel alloys are able to dissolve alloying elements, especially chromium and molybdenum, into the matrix. In contrast to iron-base alloys, nickel is able to avoid precipitation of secondary phases rich in solid-solution strengtheners such as Mo. This is why nickel-based alloys generally present superior localized corrosion resistance, compared to iron alloys. ${ }^{30,31}$

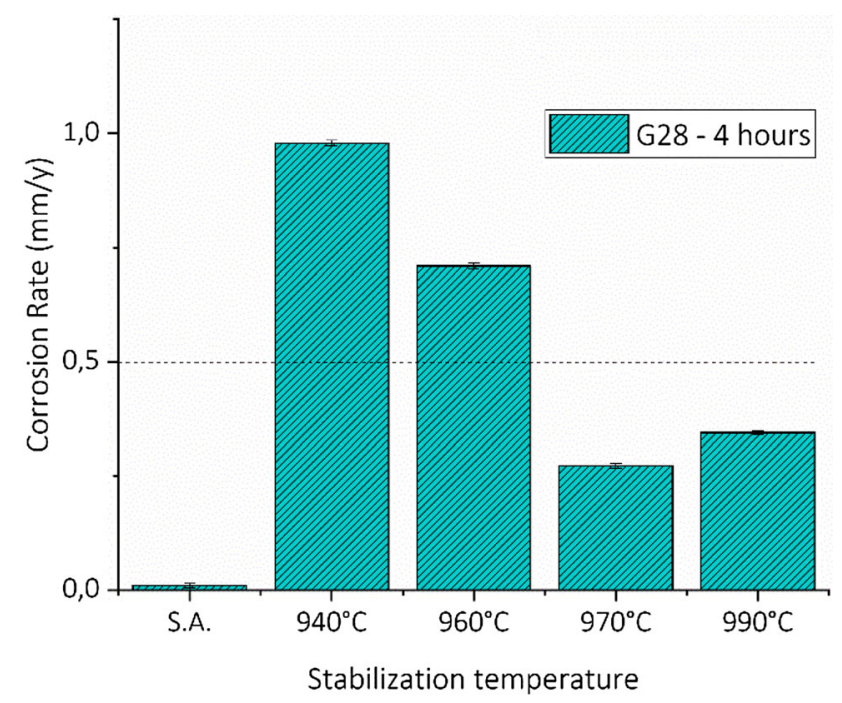

Figure 10. Corrosion rate for $4 \mathrm{~h}$ stabilized samples, given by $\mathrm{G} 28$ tests

The response to the ASTM G-28 test confirms that only a few chromium-rich compounds precipitate at the grain boundary and they are small and dispersed, in particular at the higher soaking temperatures. The similar behaviour of $940{ }^{\circ} \mathrm{C}$ and $960{ }^{\circ} \mathrm{C}$ stabilized specimens is attributable to the same precipitation behaviour: the initial formation of Mo precipitates, their growth and finally the formation of chromium compounds at grain boundary. ${ }^{22,24,32}$ According to the literature, ${ }^{24}$ corrosion rates of $0.5 \mathrm{~mm} / \mathrm{y}$ are considered acceptable for ASTM G28 testing of wrought Incoloy 825 . This means that the only acceptable values are those that correspond to specimens treated at $970{ }^{\circ} \mathrm{C}$ and $990{ }^{\circ} \mathrm{C}$. 


\section{Conclusions}

This work makes it possible to get information regarding the microstructure, mechanical response and corrosion behaviour of nickel-based CU5MCuC that has undergone different stabilization treatments. Some suggestions can be given in order to improve alloy performance and to obtain final products that satisfy ASTM-A494 requirements.

Recommendations can be made regarding the prescribed stabilization thermal treatment to be performed after solution annealing. All specimens contain precipitates rich in $\mathrm{Mo}, \mathrm{Si}$ and $\mathrm{Nb}$ and assume different morphologies according to the time-temperature combination applied, which appears to affect the mechanical and corrosion response.

$940{ }^{\circ} \mathrm{C}$ and $960{ }^{\circ} \mathrm{C}$-stabilization treatments offer the worst response to both pitting and intergranular corrosion tests. $990{ }^{\circ} \mathrm{C}$-stabilization is not recommended because of its deleterious influence on mechanical performance.

In conclusion, it can be stated that stabilization treatment performed for $4 \mathrm{~h}$ at $970{ }^{\circ} \mathrm{C}$ offers the best compromise between mechanical behaviour and corrosion resistance. The tensile strength improvement it imparts, compared to other conditions, is interesting considering that the purpose of stabilization is to prevent sensitization, but it can also be used to enhance tensile properties.

\section{Author Contributions}

All authors contributed to the study conception and design. Material preparation and data collection were performed by Claudia Fiocchi, and data analysis was performed by Andrea Gruttadauria and Silvia Barella. The first draft of the manuscript was written by Andrea Gruttadauria, and all authors commented on previous versions of the manuscript. All authors read and approved the final manuscript.

\section{Funding}

Open access funding provided by Politecnico di Milano within the CRUI-CARE Agreement.

\section{Availability of Data Materials}

Data transparency

Conflict of interest Not applicable.

\section{Open Access}

This article is licensed under a Creative Commons Attribution 4.0 International License, which permits use, sharing, adaptation, distribution and reproduction in any medium or format, as long as you give appropriate credit to the original author(s) and the source, provide a link to the Creative Commons licence, and indicate if changes were made. The images or other third party material in this article are included in the article's Creative Commons licence, unless indicated otherwise in a credit line to the material. If material is not included in the article's Creative Commons licence and your intended use is not permitted by statutory regulation or exceeds the permitted use, you will need to obtain permission directly from the copyright holder. To view a copy of this licence, visit http://creativecommons.org/ licenses/by/4.0/.

\section{REFERENCES}

1. J. Davis, Uses of Nickel (ASM International, Materials Park, 2000). https://doi.org/10.1361/ncta2000p013

2. M.J. Donachie, S.J. Donachie, Superalloys, A Technical Guide, 2nd edn. (ASM International, Materials Park, 2002)

3. R.C. Reed, The Superalloys: Fundamentals and Applications (Cambridge University Press, Cambridge, 2008)

4. J.L. Everhart, Engineering Properties of Nickel and Nickel Alloys (Springer, Berlin, 1971). https://doi.org/ 10.1007/978-1-4684-1884-2

5. B. Geddes, H. Leon, X. Huang, Superalloys: Alloying and Performance (ASM International, Materials Park, 2010)

6. M.A. Shaikh, M. Iqbal, M. Ahmad, J.I. Akhtar, K.A. Shoaib, Precipitation study of heat-treated Incoloy 825 by scanning electron microscopy. J. Mater. Sci. Lett. 11, 1009-1011 (1992). https://doi.org/10.1007/ BF00729911

7. S. Barella, A. Gruttadauria, Metallurgia e Materiali Non Metallici: Teoria ed Esercizi Svolti, Società Editrice Esculapio (2017)

8. ASTM A494/A494M-18a, Standard Specification for Castings, Nickel and Nickel Alloy (2018). https://doi. org/10.1520/a0494_a0494m-18a

9. C. Farrar, The Alloy Tree: A Guide to Low-Alloy Steels, Stainless Steels and Nickel-Base Alloys (Elsevier, Amsterdam, 2004)

10. B.D. Craig, D.S. Anderson et al., Handbook of Corrosion Data (ASM international, Materials Park, 1994)

11. Y.M. Pan, D.S. Dunn, G.A. Cragnolino, N. Sridhar, Grain-boundary chemistry and intergranular corrosion in alloy 825, Metall. Mater. Trans. A Phys. Metall. Mater. Sci. 31, 1163-1173 (2000). https://doi. org/10.1007/s11661-000-0112-4

12. J.J. Heger, J.L. Hamilton, Effect of minor constituents on the intergranular corrosion of austenitic stainless steels. Corrosion 11, 22-26 (1955) 
13. E.L. Raymond, Mechanisms of sensitization and stabilization of INCOLOY nickel-iron-chromium alloy 825. Corrosion 24, 180-188 (1968)

14. N. El-bagoury, Ni based superalloy: casting technology, metallurgy, development, properties and applications. Int. J. Eng. Sci. Res. Technol. 5, 108-152 (2016)

15. J. Belan, GCP and TCP phases presented in nickelbase superalloys. Mater. Today Proc. 3, 936-941 (2016)

16. ASTM E407-07(2015)e1, Standard Practice for Microetching Metals and Alloys (2015). https://doi. org/10.1520/e0407-07r15e01

17. ASTM E8/E8M-16ae1, Standard Test Methods for Tension Testing of Metallic Materials (2016). https:// doi.org/10.1520/e0008_e0008m-16ae01

18. ASTM G48-11(2015), Standard Test Methods for Pitting and Crevice Corrosion Resistance of Stainless Steels and Related Alloys by Use of Ferric Chloride Solution (2015). https://doi.org/10.1520/g0048$11 \mathrm{r} 15$

19. ASTM G28-02(2015), Standard Test Methods for Detecting Susceptibility to Intergranular Corrosion in Wrought, Nickel-Rich, Chromium-Bearing Alloys (2015). https://doi.org/10.1520/g0028-02r15

20. D.B. Williams, E.P. Butler, Grain boundary discontinuous precipitation reactions. Int. Met. Rev. 26, 153-180 (1981). https://doi.org/10.1179/imtr.1981. 26.1.153

21. M.J. Sohrabi, H. Mirzadeh, M. Rafiei, Revealing the As-Cast and Homogenized Microstructures of Niobium-Bearing Nickel-Based Superalloy. Int. J. Met. 13, 320-330 (2019). https://doi.org/10.1007/s40962018-0255-y

22. L.N. Zhang, J.A. Szpunar, J.X. Dong, M.C. Zhang, Influence of heat treatment on the microstructure and corrosion behavior of Ni-Fe-Cr alloy 028. J. Mater. Res. 29, 2147-2155 (2014). https://doi.org/10.1557/ jmr.2014.249

23. Sandmeyer, An Austenitic Nickel-Iron-Chromium Alloy Developed for Exceptional Corrosion Resistance in Both Oxidizing and Reducing Environments (2019). https://www.sandmeyersteel.com/images/ SSC825-Spec-Sheet.pdf. Accessed 20 Sept 2007
24. C. Zhang, L. Zhang, Y. Cui, Q. Feng, C. Cheng, Effects of high-temperature aging on precipitation and corrosion behavior of a Ni-Cr-Mo-based hastelloy C276 superalloy. J. Mater. Eng. Perform. 29, 2026-2034 (2020). https://doi.org/10.1007/s11665020-04723-y

25. L. Shoemaker, J. Crum et al., Processing and fabricating alloy 825 for optimized properties and corrosion resistance. Corrosion 2011, 1-13 (2011)

26. Y. Desvallees, M. Bouzidi, F. Bois, N. Beaude, Delta phase in INCONEL 718: mechanical properties and forging process requirements, in: Superalloys 718,625,706 Var. Deriv., TMS edited by B.A. Loria, pp. 281-291. https://doi.org/10.7449/1994/superal loys_1994_281_291

27. Y. Mu, C. Wang, W. Zhou, L. Zhou, Effect of Nb on $\delta$ phase precipitation and the tensile properties in cast alloy IN625. Metals (Basel) 8, 1-9 (2018). https://doi. org/10.3390/met8020086

28. M. Sundararaman, P. Mukhopadhyay, S. Banerjee, Precipitation of the $\delta$-Ni3Nb phase in two nickel base superalloys. Metall. Trans. A 19, 453-465 (1988). https://doi.org/10.1007/BF02649259

29. H.S. Klapper, N.S. Zadorozne, R.B. Rebak, Localized corrosion characteristics of nickel alloys: a review. Acta Metall. Sin. (English Lett.) 30, 296-305 (2017). https://doi.org/10.1007/s40195-017-0553-z

30. F. Wong, The effect of alloy composition on the localized corrosion behavior of NiCrMo alloys (The Ohio State University, Ohio, 2009)

31. D. Baker, W. Denning, G. Mirabelli, Effect of chemical composition and heat treatment on the corrosion resistance of cast nickel alloy C276. Int. J. Met. 9, 76-77 (2015). https://doi.org/10.1007/ BF03355606

32. J.R. Crum, C.S. Tassen, T. Nagashima et al., Precipitation reactions and corrosion resistance of thermally aged and welded alloy 825. Corrosion 97, 281-291 (1997)

Publisher's Note Springer Nature remains neutral with regard to jurisdictional claims in published maps and institutional affiliations. 